\title{
Factors associated with blood loss in ankylosing spondylitis patients with hip involvement undergoing primary total hip arthroplasty: a cross-sectional retrospective study of 243 patients
}

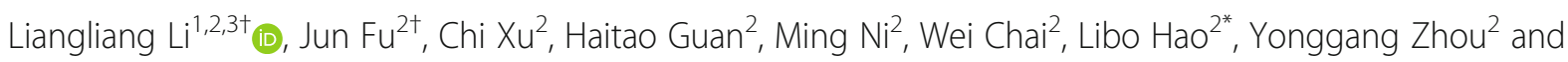 \\ Jiying Chen ${ }^{2^{*}}$
}

\begin{abstract}
Background: Total hip arthroplasty (THA) can cause considerable blood loss and perioperative transfusion in ankylosing spondylitis (AS) patients. This study aimed to identify the factors related to blood loss in AS patients with hip involvement undergoing THA.

Methods: We analyzed 243 AS patients with advanced hip involvement undergoing primary THA from 2012 to 2017. Bilateral THA was performed by a one-stage operation during one general anesthesia session. The patients were divided into three groups according to the grade of blood loss, as determined by the Advanced Trauma Life Support hypovolemic shock classification system. Ordinal logistic regression was used to identify factors associated with blood loss in the patients.
\end{abstract}

Results: The proportion of patients who were male, underwent bilateral THA, had a hip range of motion $(\mathrm{ROM})=$ $0^{\circ}$, had a BASRI-hip score of 4, underwent iliopsoas and adductor release, and underwent autologous or allogenic transfusion increased significantly with the grade of blood loss, while that of the patients who received tranexamic acid (TXA) decreased significantly $(P<0.05)$. The preoperative hemoglobin $(\mathrm{Hb})$ level, hematocrit level, and operating time also increased significantly with the grade of blood loss $(P<0.05)$. The ordinal logistic regression results identified the factors related to blood loss during THA in AS patients with hip involvement to be the male sex (odds ratio $[O R]=3.287 ; 95 \%$ confidence interval $[\mathrm{Cl}] 1.022,10.567)$, bilateral THA $(\mathrm{OR}=13.896 ; 95 \% \mathrm{Cl} 4.950$, 39.011), hip $\mathrm{ROM}=0^{\circ}(\mathrm{OR}=2.513 ; 95 \% \mathrm{Cl} 1.277,4.946)$, an elevated erythrocyte sedimentation rate (ESR) level (OR $=3.042 ; 95 \% \mathrm{Cl} 1.320,7.014)$, an elevated preoperative $\mathrm{Hb}$ level $(\mathrm{OR}=1.043 ; 95 \% \mathrm{Cl} 1.017,1.070)$, a long operating time $(\mathrm{OR}=1.009 ; 95 \% \mathrm{Cl} 1.003,1.016)$, and the administration of TXA $(\mathrm{OR}=0.252 ; 95 \% \mathrm{Cl} 0.134,0.472)$.

(Continued on next page)

\footnotetext{
*Correspondence: Haolibo301@sina.com; jiying_chen301@163.com

‘Liangliang Li and Jun Fu contributed equally to this work and are considered co-first authors.

${ }^{2}$ Department of Orthopaedics, The First Medical Centre, Chinese PLA General Hospital, Beijing, China

Full list of author information is available at the end of the article
}

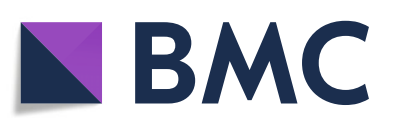

(- The Author(s). 2020 Open Access This article is licensed under a Creative Commons Attribution 4.0 International License, which permits use, sharing, adaptation, distribution and reproduction in any medium or format, as long as you give appropriate credit to the original author(s) and the source, provide a link to the Creative Commons licence, and indicate if changes were made. The images or other third party material in this article are included in the article's Creative Commons licence, unless indicated otherwise in a credit line to the material. If material is not included in the article's Creative Commons licence and your intended use is not permitted by statutory regulation or exceeds the permitted use, you will need to obtain permission directly from the copyright holder. To view a copy of this licence, visit http://creativecommons.org/licenses/by/4.0/. The Creative Commons Public Domain Dedication waiver (http://creativecommons.org/publicdomain/zero/1.0/) applies to the data made available in this article, unless otherwise stated in a credit line to the data. 


\begin{abstract}
(Continued from previous page)
Conclusions: The male sex, bilateral THA, a hip $\mathrm{ROM}=0^{\circ}$, an elevated ESR level, a high preoperative Hb level, and a long operating time are risk factors associated with blood loss in AS patients with hip involvement undergoing THA, while the administration of TXA is a protective factor. These results might help determine the risk of bleeding in the perioperative assessment and develop more efficient blood management strategies for THA in AS patients with hip involvement.
\end{abstract}

Keywords: Ankylosing spondylitis, Hip involvement, Total hip arthroplasty, Blood loss

\section{Background}

Ankylosing spondylitis (AS) is an autoimmune disease that mainly affects the axial skeleton and can affect peripheral joints $[1,2]$. The hip is the peripheral joint that is commonly involved, and hip involvement often results in severe deformities and functional disabilities due to stiffness or ankylosis [1, 2]. For advanced hip involvement, total hip arthroplasty (THA) has been proven to be an effective treatment [3-7]. Although there have been continuous improvements in anesthetic and surgical techniques, the procedure can cause considerable blood loss and perioperative transfusion. Until now, being a male, having experienced general anesthesia, having an American Society of Anesthesiologists (ASA) score of 3 , having a Charlson comorbidity index $>3$, having donated autologous blood preoperatively $[8,9]$, and having an international normalized ratio (INR) $\geq$ 1.25 [10] have been identified as clinical predictors for blood loss during THA.

In addition to these general factors, for AS patients, bleeding during THA is closely related to some characteristics of the disease itself, which mainly include the effect of systemic inflammatory activity on microvascular function and the coagulation system $[11,12]$ and the complexity of hip diseases [13]. Conventionally, the perioperative use of hemostatic $[14,15]$ and anticoagulant drugs [16] is also taken into account. Several studies have shown that bony ankylosis in the hip [13] and a higher disease activity [17] can cause an increase in bleeding during THA in AS patients, while a lower body mass index (BMI) is responsible for greater hidden blood loss postoperatively and a higher transfusion rate [18]. However, the comprehensive effects and interrelationships among these characteristic factors related to blood loss during THA in AS patients have not been reported, and whether any other factors may exist remains unclear. Thus, the current study was designed to identify the factors associated with blood loss in AS patients with hip involvement undergoing THA.

\section{Methods}

\section{Participants and data sources}

We retrospectively analyzed the data of AS patients with hip involvement who underwent primary THA in our orthopedic department from January 2012 to December 2017. This study was approved by the ethics committee of our hospital, and all the data were obtained from medical records and radiographs. AS was diagnosed on the basis of the 1984 modified New York criteria [19]. Patients who had coagulation disorders, thrombocytopenia, platelet dysfunction, a preoperative hemoglobin $(\mathrm{Hb})$ level $<90 \mathrm{~g} / \mathrm{L}$, or other hematological diseases; patients who were administered erythropoietin; and patients with chronic diseases affecting hemodynamics, such as arrhythmia and hypertension, were excluded from the study. Patients with a proximal femur deformity or a history of hip surgery or nonprimary THA were excluded as well. Ultimately, a total of 243 AS patients were enrolled. The severity of hip involvement was evaluated by the Bath Ankylosing Spondylitis Radiology Hip Index (BASRI-hip) [20] by two trained readers, according to preoperative anteroposterior pelvic radiographs. A BASRI-hip score $\geq 3$ was considered the radiographic indication for THA.

\section{Surgical technique and perioperative treatment}

The surgical indications included advanced hip involvement with pain and/or a case of hip ankylosis that limited one's ability to perform daily activities and did not respond to nonsurgical treatment. Nonsteroidal antiinflammatory drugs were discontinued at least 2 weeks before surgery. General anesthesia, the posterolateral approach, and a cementless hip prosthesis were used for all the patients. The ASA class was determined by anesthesiologists. At the start of the study period, we were not using tranexamic acid (TXA) routinely, but during the course of the study period, our practice changed and we now give an intravenous injection of $1 \mathrm{~g} \mathrm{5-10} \mathrm{min} \mathrm{before}$ the skin incision $[14,15]$. TXA was used in $65.4 \%$ of the patients in this study. A single drain was used at one operation site and was not used for more than $48 \mathrm{~h}$ postoperatively. Low-molecular-weight heparin or rivaroxaban was used for thromboprophylaxis at $10 \sim 12 \mathrm{~h}$ postoperatively, and rivaroxaban was taken orally after discharge for 35 days after the operation. For patients with a BMI $<18.5 \mathrm{~kg} / \mathrm{m}^{2}$ or APTT exceeding the top of the normal range, only mechanical anticoagulation treatment was performed. 


\section{Calculation of blood loss (CBL) and transfusion management}

Total blood loss was calculated by the following formula, as reported by Mercuriali et al. [21], where RBC and Hct are the abbreviations for red blood cell and hematocrit, respectively:

$$
\begin{aligned}
& \mathrm{CBL}(\mathrm{mL} \text { of } \mathrm{RBCs})=\mathrm{mL} \text { of blood volume }(\mathrm{BV}) \\
& \times\left(\text { Hct }_{\text {preoperative }}-\text { Hct day } 5 \text { postoperative }\right) \\
& +\mathrm{mL} \text { of RBC transfused }
\end{aligned}
$$

The RBC transfused volume was calculated as the sum of the autologous and allogenic transfusions. The predicted BV was calculated by the following formula, as described by Nadler et al. [22]:

$$
\begin{aligned}
\mathrm{BV}(\mathrm{mL})= & \left(\mathrm{k} 1 \times \text { height }^{3}+\mathrm{k} 2 \times \text { weight }+\mathrm{k} 3\right) \\
& \times 1000
\end{aligned}
$$

where height is measured in meters and weight is measured in kilograms. For men, $\mathrm{k} 1=0.3669, \mathrm{k} 2=$ 0.03219 , and $\mathrm{k} 3=0.6041$; for women, $\mathrm{k} 1=0.3561, \mathrm{k} 2=$ 0.03308 , and $\mathrm{k} 3=0.1833$.

Patients with a preoperative $\mathrm{Hb}$ level of at least $150 \mathrm{~g} /$ $\mathrm{L}$ or $130 \sim 150 \mathrm{~g} / \mathrm{L}$ aged less than 65 years were approved for an autologous blood donation [23]. The intraoperative blood loss was monitored, and the transfusion was managed by an anesthesiologist, and the postoperative criteria for a transfusion were a $\mathrm{Hb}$ level $<70 \mathrm{~g} / \mathrm{L}$ or the presence of anemic manifestations, such as a decrease in blood pressure $(<90 / 60 \mathrm{mmHg}$ ), pale lips, dizziness, weakness, and shortness of breath.

\section{Grouping criteria and assessment indicator}

The patients were divided into three groups by the grade of blood loss (grade I III $<750 \mathrm{ml}, 750 \sim 1500 \mathrm{ml}$, and > $1500 \mathrm{ml}$ ), as determined by the Advanced Trauma Life Support (ATLS) hypovolemic shock classification system [24]. Clinical characteristics, preoperative laboratory values, and perioperative data were compared among the three groups. The clinical characteristics included age, sex, BMI, disease duration, bilateral THA, hip range of motion $(\mathrm{ROM})=0^{\circ}$, and a BASRI-hip of 4 (on any one side). The preoperative laboratory values included the erythrocyte sedimentation rate (ESR), C-reactive protein (CRP) level, thromboplastin time (TT), activated partial thromboplastin time (APTT), prothrombin time (PT), prothrombin activity (PT\%), INR, fibrinogen concentration, platelet level, $\mathrm{Hb}$ level, and hematocrit (Hct). Elevated ESR and CRP levels were defined as follows: ESR > $15 \mathrm{~mm} / \mathrm{h}$ for males and $>20 \mathrm{~mm} / \mathrm{h}$ for females and CRP $>1 \mathrm{mg} / \mathrm{dL}$. The perioperative data comprised data on iliopsoas and adductor release, the administration of TXA, chemoprophylaxis for thrombosis, the operating time, autologous transfusion, allogenic transfusion, and the ASA class.

\section{Statistical analysis}

One-way ANOVA was used to compare continuous, normally distributed variables (mean \pm standard deviation), while the Wilcoxon rank sum test was used to compare non-normally distributed, continuous variables (median, minimum to maximum). The chi-square test or Fisher's exact test was used to compare the categorical and dichotomous variables. Ordinal logistic regression was performed to identify factors associated with blood loss in AS patients with hip involvement undergoing THA. All statistical analyses were performed with IBM SPSS statistics for Windows, version 25.0 (IBM, Armonk, NY, USA). A $P$ value $<0.05$ was considered statistically significant.

\section{Results}

The admission age, disease duration, and BMI ranged from 19 to 76 years (median, 32 years), 0.5 to 40.3 years (median, 11 years), and 11.87 to $37.11 \mathrm{~kg} / \mathrm{m}^{2}$ (median, $\left.22.64 \mathrm{~kg} / \mathrm{m}^{2}\right)$, respectively. There were $218(89.7 \%)$ male patients. A total of $163(67.1 \%)$ patients underwent bilateral THA, $121(49.8 \%)$ patients had a $\mathrm{ROM}=0^{\circ}$ in the hip, and $38(15.6 \%)$ patients had a history of smoking. Of all the involved hips, there were 178 (43.8\%) and 228 (56.2\%) hips with BASRI-hip scores of 3 and 4, respectively. Iliopsoas and adductor release were performed in $41(16.9 \%)$ patients, periprosthetic fracture occurred in 10 (4.1\%) patients, TXA was administered in 159 (65.4\%) patients, and chemoprophylaxis for thrombosis was administered in 183 (75.3\%) patients. Autologous and allogenic transfusions were performed in $66(27.2 \%)$ and 229 (94.2\%) patients, $13.8 \%$ and $32.5 \%$ and $83.8 \%$ and 99.4\% of whom underwent unilateral and bilateral THA, respectively. The operating time $(90,55$ to $285 \mathrm{~min}$ vs 205, 70 to $455 \mathrm{~min})$ and blood loss $(790 \pm 342 \mathrm{~mL}$ vs $1435 \pm 495 \mathrm{~mL}$ ) were also calculated for the patients who underwent unilateral and bilateral THA separately (Table 1).

The proportion of patients who were male, underwent bilateral THA, had a hip ROM $=0^{\circ}$, had a BASRI-hip score of 4, underwent iliopsoas and adductor release, underwent autologous transfusion, and underwent allogenic transfusion increased significantly with the grade of blood loss, while that of patients who were administered tranexamic acid (TXA) decreased significantly $(P<$ 0.05). There were significant differences in TT, APTT, fibrinogen level, platelet level, and proportion of patients who underwent chemoprophylaxis for thrombosis among the three groups $(P<0.05)$. The frequency of an elevated ESR in group II was higher than those in the other two groups, and the difference approached 
Table 1 Baseline characteristics of the AS patients with hip involvement undergoing THA

\begin{tabular}{|c|c|c|}
\hline Baseline characteristic & Values $^{\mathrm{a}}$ & Range $^{b}$ \\
\hline \multicolumn{3}{|l|}{ Clinical characteristics } \\
\hline Age (years) & 32 & 19 to 67 \\
\hline Male $(n, \%)$ & $218(89.7 \%)$ & \\
\hline $\mathrm{BMI}\left(\mathrm{kg} / \mathrm{m}^{2}\right)$ & 22.64 & 11.87 to 37.11 \\
\hline Disease duration (years) & 11 & 0.5 to 40.3 \\
\hline Hospital stay (days) & 11 & 6 to 46 \\
\hline Smoking history $(n, \%)$ & $38(15.6 \%)$ & \\
\hline Bilateral THA $(n, \%)$ & $163(67.1 \%)$ & \\
\hline Hip ROM $=0^{\circ}(n, \%)$ & $121(49.8 \%)$ & \\
\hline \multicolumn{3}{|l|}{$\begin{array}{l}\text { BASRI-hip (number of cases at } \\
\text { involved hip) }\end{array}$} \\
\hline $3(n, \%)$ & $178(43.8 \%)$ & \\
\hline $4(n, \%)$ & $228(56.2 \%)$ & \\
\hline \multicolumn{3}{|l|}{ Preoperative laboratory values } \\
\hline $\begin{array}{l}\text { Elevated ESR level (> } 15 \mathrm{~mm} / \mathrm{h} \text { for } \\
\text { male and }>20 \mathrm{~mm} / \mathrm{h} \text { for female, } n, \%)\end{array}$ & 132 (54.3\%) & 1 to 99 \\
\hline Elevated CRP level (> $1 \mathrm{mg} / \mathrm{dL}, n, \%)$ & $165(67.9 \%)$ & 0.1 to 11.6 \\
\hline$\Pi(\mathrm{s})$ & $16.1 \pm 1.0$ & 12.3 to 19.4 \\
\hline APTT (s) & $40.4 \pm 4.9$ & 30.3 to 54.0 \\
\hline PT (s) & $13.5 \pm 0.8$ & 11.4 to 16.2 \\
\hline PT (\%) & $94.4 \pm 12.0$ & 63.6 to 123.0 \\
\hline INR & $1.05 \pm 0.08$ & 0.88 to 1.30 \\
\hline Fibrinogen level (g/L) & 4.23 & 1.76 to 13.10 \\
\hline Platelet level $\left(\times 10^{9} / \mathrm{L}\right)$ & $273 \pm 72$ & 103 to 509 \\
\hline Hb level $(g / L)$ & $133 \pm 16$ & 90 to 171 \\
\hline $\operatorname{Hct}(L / L)$ & $0.404 \pm 0.043$ & 0.284 to 0.512 \\
\hline \multicolumn{3}{|l|}{ Perioperative data } \\
\hline Periprosthetic fracture $(n, \%)$ & $10(4.1 \%)$ & \\
\hline Iliopsoas and adductor release $(n, \%)$ & $41(16.9 \%)$ & \\
\hline Administration of TXA $(n, \%)$ & $159(65.4 \%)$ & \\
\hline Chemoprophylaxis of thrombosis $(n, \%)$ & $183(75.3 \%)$ & \\
\hline Autologous transfusion $(n, \%)$ & $66(27.2 \%)$ & \\
\hline Unilateral THA $(n=80)$ & $11(13.8 \%)$ & \\
\hline Bilateral THA $(n=163)$ & $53(32.5 \%)$ & \\
\hline Allogenic transfusion $(n, \%)$ & $229(94.2 \%)$ & \\
\hline Unilateral THA $(n=80)$ & $67(83.8 \%)$ & \\
\hline Bilateral THA $(n=163)$ & $162(99.4 \%)$ & \\
\hline Operating time (min) & 180 & 55 to 455 \\
\hline Unilateral THA & 90 & 55 to 285 \\
\hline Bilateral THA & 205 & 70 to 455 \\
\hline $\mathrm{CBL}(\mathrm{mL})$ & $1223 \pm 542$ & 162 to 3098 \\
\hline Unilateral THA & $790 \pm 342$ & 162 to 1901 \\
\hline Bilateral THA & $1435 \pm 495$ & 453 to 3098 \\
\hline
\end{tabular}

AS ankylosing spondylitis, THA total hip arthroplasty, BMI body mass index, ROM range of motion, BASRI-hip Bath Ankylosing Spondylitis Radiology Hip Index, ESR erythrocyte sedimentation rate, CRP C-reactive protein, $\pi$ thromboplastin time, APTT activated partial thromboplastin time, $P T$ prothrombin time, $P T \%$ prothrombin activity, INR international normalized ratio, $\mathrm{Hb}$ hemoglobin, $\mathrm{Hct}$ hematocrit, TXA tranexamic acid, $B V$ blood volume, $C B L$ calculated blood loss

${ }^{a}$ Mean \pm SD or median

${ }^{b}$ Minimum to maximum statistical significance $(P=0.058)$. The same trend was found in the frequency of an elevated level of CRP, but the difference was not significant $(P=0.168)$. The $\mathrm{Hb}$ level, Hct level, and operating time also increased significantly with the grade of blood loss $(P<0.05)$. No significant differences were found in BMI, disease duration, PT, PT \%, INR, or ASA class among the three groups $(P>0.05)$ (Table 2).

The ordinal logistic regression results showed that the factors associated with blood loss in AS patients with hip involvement undergoing THA are the male sex (odds ratio $[\mathrm{OR}]=3.287 ; 95 \%$ confidence interval $[\mathrm{CI}], 1.022$ to 10.567), bilateral THA (OR $=13.896 ; 95 \% \mathrm{CI}, 4.950$ to 39.011), hip $\mathrm{ROM}=0^{\circ}(\mathrm{OR}=2.513 ; 95 \% \mathrm{CI}, 1.277$ to 4.946), an elevated ESR level (OR $=3.042 ; 95 \% \mathrm{CI}, 1.320$ to 7.014), an elevated preoperative $\mathrm{Hb}$ level $(\mathrm{OR}=1.043$; $95 \% \mathrm{CI}, 1.017$ to 1.070$)$, a long operating time (OR = 1.009; $95 \% \mathrm{CI}, 1.003$ to 1.016), and the administration of TXA $(\mathrm{OR}=0.252 ; 95 \% \mathrm{CI}, 0.134$ to 0.472$)$ (Table 3$)$.

\section{Discussion}

THA has been proven to be extremely effective in treating AS patients with advanced hip involvement [3-7], while the large volume of blood loss is a consequence that should be addressed. The blood loss calculated in our study included that of all the bleeding events: intraoperative blood loss, postoperative drainage, and "hidden" blood loss [25]. As mentioned, bony ankylosis at the hip [13] and a higher disease activity [17] increase bleeding during THA in AS patients. Owing to the characteristic differences between AS and other hip diseases requiring THA, we hypothesized that disease activity, the severity of hip disease, and the administration of perioperative medication might be associated with perioperative bleeding in AS patients. Thus, we conducted this relatively comprehensive research on factors related to blood loss during THA in AS patients with hip involvement.

The results of this study indicate that the male sex, bilateral THA, hip ROM $=0^{\circ}$, an elevated ESR level, an elevated preoperative $\mathrm{Hb}$ level, and long operating time are risk factors associated with blood loss in AS patients with hip involvement undergoing THA, while the administration of TXA is a protective factor. Being a male is a risk factor for two possible reasons. First, the population of individuals with AS with advanced hip involvement is predominantly male [26]. Second, the average preoperative $\mathrm{Hb}$ level is higher in men than in women, as we also identified that an elevated preoperative $\mathrm{Hb}$ level is related to bleeding during THA in AS patients. Generally, after bleeding and the blood transfusion process is complete, the $\mathrm{Hb}$ levels should remain above the lower limit of the normal range, and patients should not have symptoms of hypovolemic shock. Therefore, 
Table 2 Comparison of the clinical characteristics, preoperative laboratory values, and perioperative data among the 3 groups stratified by the grade of blood loss, as determined by the ATLS hypovolemic shock classification system

\begin{tabular}{|c|c|c|c|c|}
\hline & \multicolumn{3}{|l|}{ Grade of blood loss } & \multirow[t]{2}{*}{$P$ value } \\
\hline & $\mathrm{I}<750 \mathrm{ml}(n=49)$ & II 750 1500 ml $(n=121)$ & III> $1500 \mathrm{ml}(n=73)$ & \\
\hline \multicolumn{5}{|l|}{ Clinical characteristics } \\
\hline Age (years) & 32 (19 to 67$)$ & 32 (19 to 59$)$ & 34 (22 to 53$)$ & $0.449^{c}$ \\
\hline Male $(n, \%)$ & 37 (75.5\%) & $110(90.9 \%)$ & $71(97.3 \%)$ & $<0.0001^{a}$ \\
\hline BMI $\left(\mathrm{kg} / \mathrm{m}^{2}\right)$ & 21.83 (11.87 to 36.73$)$ & $22.76(15.06$ to 36.98$)$ & 23.39 (15.22 to 37.11$)$ & $0.078^{c}$ \\
\hline Disease duration (years) & $10(0.5$ to 40.3$)$ & 10.5 (1.0 to 30.0$)$ & 14 (0.5 to 34$)$ & $0.114^{c}$ \\
\hline Bilateral THA $(n, \%)$ & $8(16.3 \%)$ & $84(69.4 \%)$ & $71(97.3 \%)$ & $<0.0001^{\mathrm{a}}$ \\
\hline Hip $\mathrm{ROM}=0^{\circ}(n, \%)$ & $10(20.4 \%)$ & $60(49.6 \%)$ & $51(69.9 \%)$ & $<0.0001^{a}$ \\
\hline BASRI-hip score of $4(n, \%)$ & $16(32.7 \%)$ & $68(56.2 \%)$ & 55 (75.3\%) & $<0.0001^{a}$ \\
\hline \multicolumn{5}{|l|}{ Preoperative laboratory values } \\
\hline Elevated level of ESR $(n, \%)$ & $23(46.9 \%)$ & $75(62.0 \%)$ & $34(46.6 \%)$ & $0.058^{\mathrm{a}}$ \\
\hline Elevated level of CRP $(n, \%)$ & $31(63.3 \%)$ & $89(73.6 \%)$ & $45(61.6 \%)$ & $0.168^{\mathrm{a}}$ \\
\hline$\Pi(s)$ & $15.7 \pm 0.8$ & $16.2 \pm 1.0$ & $16.2 \pm 1.0$ & $0.013^{b}$ \\
\hline APTT (s) & $40.6 \pm 4.8$ & $41.4 \pm 4.7$ & $38.7 \pm 4.9$ & $0.001^{b}$ \\
\hline PT (s) & $13.6 \pm 0.8$ & $13.5 \pm 0.8$ & $13.4 \pm 0.9$ & $0.206^{b}$ \\
\hline PT (\%) & $93.2 \pm 11.3$ & $93.9 \pm 11.9$ & $96.1 \pm 12.7$ & $0.346^{b}$ \\
\hline INR & $1.06 \pm 0.08$ & $1.05 \pm 0.08$ & $1.03 \pm 0.08$ & $0.219^{b}$ \\
\hline Fibrinogen level (g/L) & 4.04 (2.42 to 7.41$)$ & $4.45(1.90$ to 13.10$)$ & $4.06(1.76$ to 6.16$)$ & $0.014^{c}$ \\
\hline Platelet level $\left(\times 10^{9} / \mathrm{L}\right)$ & $270 \pm 67$ & $289 \pm 77$ & $249 \pm 58$ & $0.001^{b}$ \\
\hline Hb level (g/L) & $127 \pm 15$ & $131 \pm 16$ & $140 \pm 16$ & $<0.0001^{\mathrm{b}}$ \\
\hline $\mathrm{Hct}(\mathrm{L} / \mathrm{L})$ & $0.386 \pm 0.041$ & $0.401 \pm 0.042$ & $0.423 \pm 0.041$ & $<0.0001^{\mathrm{b}}$ \\
\hline \multicolumn{5}{|l|}{ Perioperative data } \\
\hline Iliopsoas and adductor release $(n, \%)$ & $2(4.1 \%)$ & $23(19.0 \%)$ & $16(21.9 \%)$ & $0.024^{\mathrm{a}}$ \\
\hline Administration of TXA $(n, \%)$ & $40(81.6 \%)$ & $77(63.6 \%)$ & $42(57.5 \%)$ & $<0.0001^{a}$ \\
\hline Chemoprophylaxis of thrombosis $(n, \%)$ & $30(61.2 \%)$ & $97(80.2 \%)$ & $56(76.7 \%)$ & $0.033^{\mathrm{a}}$ \\
\hline Operating time (min) & 100 (55 to 250$)$ & $180(60$ to 335$)$ & 210 (70 to 455$)$ & $<0.0001^{c}$ \\
\hline Autologous transfusion $(n, \%)$ & $3(6.1 \%)$ & $30(24.8 \%)$ & $33(45.2 \%)$ & $<0.0001^{a}$ \\
\hline Allogenic transfusion $(n, \%)$ & $37(75.5 \%)$ & $119(98.3 \%)$ & $73(100 \%)$ & N/A \\
\hline ASA class & & & & $0.672^{\mathrm{a}}$ \\
\hline 1 & 5 & 6 & 4 & \\
\hline 2 & 40 & 105 & 65 & \\
\hline 3 & 4 & 10 & 4 & \\
\hline
\end{tabular}

ATLS Advanced Trauma Life Support, AS ankylosing spondylitis, THA total hip arthroplasty, BMI body mass index, ROM range of motion, BASRI-hip Bath Ankylosing Spondylitis Radiology Hip Index, ESR erythrocyte sedimentation rate, CRP C-reactive protein, $\Pi$ thromboplastin time, $A P T T$ activated partial thromboplastin time, PT prothrombin time, PT\% prothrombin activity, INR international normalized ratio, Hb hemoglobin, Hct hematocrit, TXA tranexamic acid, ASA American Society of Anesthesiologists

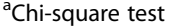

bone-way ANOVA

'Wilcoxon rank sum test

according to the principle of $\mathrm{Hb}$ balance, a higher preoperative $\mathrm{Hb}$ level is expected to result in more blood loss. In addition, autologous transfusion can be a beneficial choice for patients with an elevated preoperative $\mathrm{Hb}$ level, as shown in our practice. However, autologous transfusion only is insufficient, and allogenic blood transfusion is also needed. The total allogenic transfusion rate in this study is higher than reported in other studies $[13,17,18]$, which is mainly due to the higher proportion of patients undergoing bilateral THA compared with unilateral THA (approximately $2 / 3$ ). If the allogenic transfusion rate in only patients who underwent unilateral THA is compared between this study and the studies mentioned, our results are comparable. 
Table 3 Ordinal logistic regression of the risk factors for blood loss in AS patients with hip involvement undergoing THA

\begin{tabular}{lll}
\hline Parameter & OR (95\% Cl) & $\boldsymbol{P}$ value \\
\hline Male sex & $3.287(1.022$ to 10.567$)$ & $\mathbf{0 . 0 4 6}$ \\
BMI & $0.960(0.897$ to 1.027$)$ & 0.236 \\
Bilateral THA & $13.896(4.950$ to 39.011$)$ & $<\mathbf{0 . 0 0 0 1}$ \\
Hip ROM $=0^{\circ}$ & $2.513(1.277$ to 4.946$)$ & $\mathbf{0 . 0 0 8}$ \\
BASRI-hip score of 4 & $0.700(0.345$ to 1.421$)$ & 0.324 \\
Elevated ESR level & $3.042(1.320$ to 7.014$)$ & $\mathbf{0 . 0 0 9}$ \\
Elevated CRP level & $0.885(0.415$ to 1.888$)$ & 0.752 \\
TT (s) & $1.189(0.880$ to 1.606$)$ & 0.260 \\
APTT (s) & $0.964(0.901$ to 1.032$)$ & 0.291 \\
Fibrinogen(g/L) & $0.780(0.562$ to 1.081$)$ & 0.136 \\
Platelet level( $\left.\times 10^{9} / \mathrm{L}\right)$ & $0.997(0.992$ to 1.002$)$ & 0.211 \\
Preoperative Hb level (g/L) & $1.043(1.017$ to 1.070$)$ & $\mathbf{0 . 0 0 1}$ \\
\|liopsoas and adductor release & $1.934(0.860$ to 4.350$)$ & 0.111 \\
Administration of TXA & $0.252(0.134$ to 0.472$)$ & $<\mathbf{0 . 0 0 0 1}$ \\
Chemoprophylaxis of thrombosis & $1.814(0.896$ to 3.674$)$ & 0.098 \\
Operating time (min) & $1.009(1.003$ to 1.016$)$ & $\mathbf{0 . 0 0 4}$ \\
\hline AS anky &
\end{tabular}

AS ankylosing spondylitis, THA total hip arthroplasty, OR odds ratio, $\mathrm{Cl}$ confidence interval, BMI body mass index, ROM range of motion, BASRI-hip Bath Ankylosing Spondylitis Radiology Hip Index, ESR erythrocyte sedimentation rate, $C R P$ C-reactive protein, $\pi$ thromboplastin time, APTI activated partial thromboplastin time, $H b$ hemoglobin, TXA tranexamic acid

In our department, the operations were mainly performed by a one-stage operation during one general anesthesia session in patients requiring THA at both hips. Bilateral THA can cause more bleeding than unilateral THA, but several studies have suggested that the total blood loss is significantly lower in patients undergoing a one-stage procedure than in those undergoing a two-stage procedure, and surgeons are probably more concerned about bleeding during a one-stage procedure and therefore take more care to ensure hemostasis [27, 28]. Additionally, the bilateral procedure not only reduces the costs and hospital stay [28] but also yields optimal function in patients with bilateral hip disease [29]. Hence, because the bleeding volume can be more reasonably predicted, appropriate blood management is performed, and hemostasis is ensured during the operation; bilateral THA is still a top option for AS patients who need surgical treatment for both hips.

The reduction in the hip ROM is a characteristic clinical manifestation of severe hip involvement in AS cases. A hip $\mathrm{ROM}=0^{\circ}$, which is considered the external manifestation of hip ankylosis, is a marked risk factor associated with blood loss during THA. During the procedure for hip ankylosis, the femoral head cannot be dislocated after exposure, which means that a two-step osteotomy must be performed to ream the acetabulum. A two-step osteotomy increases the operating time, and a long operation at the cancellous bone interface causes increased intraoperative bleeding. To minimize bleeding at the osteotomy surface, we sealed it with bone wax after the first osteotomy and then performed the second osteotomy and acetabulum preparation. Moreover, a long operating time is also a risk factor for excessive bleeding during THA in AS patients. Thus, stanching bleeding at the osteotomy interface and shortening the operating time are important for reducing perioperative bleeding and postoperative transfusion.

ESR and CRP are biomarkers of inflammatory diseases that are commonly examined and can reflect the disease activity to some extent. Similar to $\mathrm{Hu}$ et al. [17], we determined that an elevated ESR level is a risk factor for blood loss in AS patients with end-stage hip disease undergoing THA. The frequency of elevated ESR level was higher in group II and did not gradually increase with the grade of blood loss, which could be interpreted as follows: patients in that group were mainly at the transition period from mid- to end-stage AS. This period is the stage during which hip involvement in AS cases is aggravated and accompanied by higher disease activity, which is characterized by continuous narrowing of the joint space until bony ankylosis develops. When the articular cartilage is completely damaged, the disease activity declines [30]. Therefore, it is recommended that ESR level is decreased as much as possible before THA under the care of rheumatologists.

The clinical administration of TXA can effectively reduce perioperative blood loss and the transfusion rate during THA [14, 15, 31-33]. Likewise, we confirmed that the administration of TXA is a protective factor for blood loss during THA in AS patients. Several studies have shown that the administration of TXA does not increase the risk of deep vein thrombosis, pulmonary embolism, or other complications [34, 35], regardless of whether routine chemical thromboprophylaxis is administered after primary THA $[36,37]$. In recent years, we also used TXA topically in the surgical fields or intra-articularly before the surgical wounds were closed $[38,39]$, but TXA was administered by an intravenous injection in this study. In addition, we found that the administration of chemical thromboprophylaxis had no effect on total blood loss during THA, but this factor still needs to be studied further.

Several limitations exist in this study. First, patients were administered TXA and chemical thromboprophylaxis by different surgeons, which can lead to selection bias. TXA has been routinely used in our department in recent years, but it was not used routinely at the beginning of this study period. Second, this is a single-center study, which may lead to admission bias.

In conclusion, our study determined that the male sex, bilateral THA, hip ROM $=0^{\circ}$, an elevated ESR level, an elevated preoperative $\mathrm{Hb}$ level, and long operating time are risk factors associated with blood loss in AS patients 
with hip involvement undergoing THA, while the administration of TXA is a protective factor. Since the preoperative $\mathrm{Hb}$ level is related to bleeding, it may be beneficial to prepare for autologous transfusion for patients with a higher preoperative $\mathrm{Hb}$ level. These results may help determine the risk of bleeding in perioperative assessments and develop more efficient blood management strategies for THA in AS patients with hip involvement.

\section{Abbreviations \\ AS: Ankylosing spondylitis; THA: Total hip arthroplasty; BMI: Body mass index; ROM: Range of motion; BASRI-hip: Bath Ankylosing Spondylitis Radiology Hip Index; ESR: Erythrocyte sedimentation rate; CRP: C-reactive protein; TT: Thromboplastin time; APTT: Activated partial thromboplastin time; PT: Prothrombin time; PT\%: Prothrombin activity; INR: International normalized ratio; Hb: Hemoglobin; Hct: Hematocrit; TXA: Tranexamic acid; BV: Blood volume; CBL: Calculated blood loss; ASA: American Society of Anesthesiologists; OR: Odds ratio; Cl: Confidence interval}

\section{Acknowledgements}

The authors would like to thank Dr. Xiyue Chen and Dr. Xiang Huang for their help with the data collection.

\section{Authors' contributions}

LLL designed the study and wrote the article. GHT was responsible for retrieving the original data of all the AS patients with hip involvement undergoing THA. FJ, XC, and NM participated in the analysis of the data and contributed to the interpretation of results. The operations were mainly performed by $C W, H L B, Z Y G$, and CJY, who were the four experienced senior surgeons in our department. All authors read and approved the final manuscript.

\section{Funding}

This work was supported by the military medical and health achievements expansion test [grant numbers 19WKS09].

\section{Availability of data and materials}

All data generated or analyzed during this study are included in this published article.

\section{Ethics approval and consent to participate}

This study was approved by the ethics committee of Chinese PLA general hospital. Consent to participate is not applicable for this retrospective study.

\section{Consent for publication}

Not applicable.

\section{Competing interests}

The authors declare that they have no competing interests.

\section{Author details}

'Medical School of Chinese PLA, Beijing, China. ${ }^{2}$ Department of Orthopaedics, The First Medical Centre, Chinese PLA General Hospital, Beijing, China. ${ }^{3}$ Department of Orthopaedics, The Second Hospital of Shanxi Medical University, Taiyuan, Shanxi, China.

Received: 3 September 2020 Accepted: 2 November 2020 Published online: 18 November 2020

\section{References}

1. Marks JS, Hardinge K. Clinical and radiographic features of spondylitic hip disease. Ann Rheum Dis. 1979;38:332-6. https://doi.org/10.1136/ard.38.4.332.

2. Vander Cruyssen B, Muñoz-Gomariz E, Font $P$, et al. Hip involvement in ankylosing spondylitis: epidemiology and risk factors associated with hip replacement surgery. Rheumatology (Oxford). 2010;49:73-81. https://doi.org/ 10.1093/rheumatology/kep174.

3. Sochart DH, Porter ML. Long-term results of total hip replacement in young patients who had ankylosing spondylitis. Eighteen to thirty-year results with survivorship analysis. J Bone Joint Surg Am. 1997;79:1181-9. https://doi.org/ 10.2106/00004623-199708000-00010.

4. Bhan S, Eachempati KK, Malhotra R. Primary cementless total hip arthroplasty for bony ankylosis in patients with ankylosing spondylitis. J Arthroplasty. 2008;23:859-66. https://doi.org/10.1016/j.arth.2007.07.014

5. Guo H-Z, Yang C-X, Tang Z-P. Wang C-X. The effects of total hip arthroplasty in treating hip bony fusion in young and middle-aged patients with ankylosing spondylitis. J Orthop Surg Res. 2019;14:253. https://doi.org/ 10.1186/s13018-019-1288-5

6. Bangjian H, Peijian T, Ju L. Bilateral synchronous total hip arthroplasty for ankylosed hips. Int Orthop. 2012;36:697-701. https://doi.org/10.1007/s00264011-1313-8

7. Feng D, Zhang $K$, Zhang $Y$, et al. Bilaterally primary cementless total hip arthroplasty for severe hip ankylosis with ankylosing spondylitis. Orthop Surg. 2016:8:352-9. https://doi.org/10.1111/os.12254.

8. Grosflam JM, Wright EA, Cleary PD, Katz JN. Predictors of blood loss during total hip replacement surgery. Arthritis Care Res. 1995:8:167-73. https://doi. org/10.1002/art.1790080309.

9. Park JH, Rasouli MR, Mortazavi SMJ, et al. Predictors of perioperative blood loss in total joint arthroplasty. J Bone Joint Surg Am. 2013;95:1777-83. https://doi.org/10.2106/JBJS.L.01335.

10. Rudasill SE, Liu J, Kamath AF. Revisiting the international normalized ratio threshold for bleeding risk and mortality in primary total hip arthroplasty: a national surgical quality improvement program analysis of 17,567 patients. J Bone Joint Surg Am. 2020;102:52-9. https://doi.org/10.2106/JBJS.19.00160.

11. van Eijk IC, Peters MJL, Serné EH, et al. Microvascular function is impaired in ankylosing spondylitis and improves after tumour necrosis factor alpha blockade. Ann Rheum Dis. 2009;68:362-6. https://doi.org/10.1136/ard.2007.086777.

12. So AK, Varisco P-A, Kemkes-Matthes B, et al. Arthritis is linked to local and systemic activation of coagulation and fibrinolysis pathways. J Thromb Haemost. 2003;1:2510-5. https://doi.org/10.1111/j.1538-7836.2003.00462.x.

13. Li J, Zhao J, He C, et al. Comparison of blood loss after total hip arthroplasty between ankylosing spondylitis and osteoarthritis. J Arthroplasty. 2016;31: 1504-9. https://doi.org/10.1016/j.arth.2015.12.049.

14. Rajesparan K, Biant LC, Ahmad M, Field RE. The effect of an intravenous bolus of tranexamic acid on blood loss in total hip replacement. J Bone Joint Surg Br. 2009;91:776-83. https://doi.org/10.1302/0301-620X.91B6.22393.

15. Yamasaki S, Masuhara K, Fuji T. Tranexamic acid reduces postoperative blood loss in cementless total hip arthroplasty. J Bone Joint Surg Am. 2005; 87:766-70. https://doi.org/10.2106/JBJS.D.02046.

16. Geerts WH, Pineo GF, Heit JA, et al. Prevention of venous thromboembolism: the Seventh ACCP Conference on Antithrombotic and Thrombolytic Therapy. Chest. 2004;126:338S-400S. https://doi.org/10.1378/ chest.126.3_suppl.338S.

17. Hu Y, Jiang W-Z, Pan C-L, Wang T. Active ankylosing spondylitis increases blood loss during total hip arthroplasty for a stiff hip joint. BMC Musculoskelet Disord. 2020;21:243. https://doi.org/10.1186/s12891-02003278-2.

18. Zhao J, Li J, Zheng W, et al. Low body mass index and blood loss in primary total hip arthroplasty: results from 236 consecutive ankylosing spondylitis patients. Biomed Res Int. 2014;2014:742393. https://doi.org/10. 1155/2014/742393.

19. van der Linden S, Valkenburg HA, Cats A (1984) Evaluation of diagnostic criteria for ankylosing spondylitis. A proposal for modification of the New York criteria. Arthritis Rheum 27:361-368. doli: https://doi.org/10.1002/art. 1780270401

20. MacKay K, Brophy S, Mack C, et al. The development and validation of a radiographic grading system for the hip in ankylosing spondylitis: the bath ankylosing spondylitis radiology hip index. J Rheumatol. 2000;27:2866-72.

21. Mercuriali F, Inghilleri G. Proposal of an algorithm to help the choice of the best transfusion strategy. Curr Med Res Opin. 1996;13:465-78. https://doi. org/10.1185/03007999609115227

22. Nadler SB, Hidalgo $\mathrm{JH}$, Bloch T. Prediction of blood volume in normal human adults. Surgery. 1962;51:224-32.

23. Hatzidakis AM, Mendlick RM, McKillip T, et al. Preoperative autologous donation for total joint arthroplasty. An analysis of risk factors for allogenic transfusion. J Bone Joint Surg Am. 2000;82:89-100. https://doi.org/10.2106/ 00004623-200001000-00011.

24. Lawton LD, Roncal S, Leonard E, et al. The utility of Advanced Trauma Life Support (ATLS) clinical shock grading in assessment of trauma. Emerg Med J. 2014;31:384-9. https://doi.org/10.1136/emermed-2012-201813. 
25. Null S, Null E, Null N. How much blood is really lost in total knee arthroplasty? Correct blood loss management should take hidden loss into account. Knee. 2000;7:151-5. https://doi.org/10.1016/s0968-0160(00)00047-8.

26. Chen D, Yuan S, Zhan Z, et al. Early-stage hip involvement in patients with ankylosing spondylitis: a Chinese study based on magnetic resonance imaging. Mod Rheumatol. 2016;26:933-9. https://doi.org/10.3109/14397595. 2016.1153232

27. Bhan S, Pankaj A, Malhotra R. One- or two-stage bilateral total hip arthroplasty: a prospective, randomised, controlled study in an Asian population. J Bone Joint Surg Br. 2006;88:298-303. https://doi.org/10.1302/ 0301-620X.88B3.17048.

28. Alfaro-Adrián J, Bayona F, Rech JA, Murray DW. One- or two-stage bilateral total hip replacement. J Arthroplasty. 1999;14:439-45. https://doi.org/10. 1016/s0883-5403(99)90099-2.

29. Wykman A, Olsson E. Walking ability after total hip replacement. A comparison of gait analysis in unilateral and bilateral cases. J Bone Joint Surg Br. 1992;74:53-6.

30. Appel H, Kuhne M, Spiekermann S, et al. Immunohistochemical analysis of hip arthritis in ankylosing spondylitis: evaluation of the bone-cartilage interface and subchondral bone marrow. Arthritis Rheum. 2006;54:1805-13. https://doi.org/10.1002/art.21907.

31. Ralley FE, Berta D, Binns V, et al. One intraoperative dose of tranexamic acid for patients having primary hip or knee arthroplasty. Clin Orthop Relat Res. 2010;468:1905-11. https://doi.org/10.1007/s11999-009-1217-8.

32. Johansson T, Pettersson L-G, Lisander B. Tranexamic acid in total hip arthroplasty saves blood and money: a randomized, double-blind study in 100 patients. Acta Orthop. 2005;76:314-9.

33. Imai N, Dohmae Y, Suda K, et al. Tranexamic acid for reduction of blood loss during total hip arthroplasty. J Arthroplasty. 2012;27:1838-43. https:// doi.org/10.1016/j.arth.2012.04.024.

34. Sukeik M, Alshryda S, Haddad FS, Mason JM. Systematic review and metaanalysis of the use of tranexamic acid in total hip replacement. J Bone Joint Surg Br. 2011;93:39-46. https://doi.org/10.1302/0301-620X.93B1.24984.

35. Porter SB, White LJ, Osagiede $O$, et al. Tranexamic acid administration is not associated with an increase in complications in high-risk patients undergoing primary total knee or total hip arthroplasty: a retrospective case-control study of 38,220 patients. J Arthroplasty. 2020;35:45-51.e3. https://doi.org/10.1016/j.arth.2019.08.015.

36. Kim Y-H, Park J-W, Kim J-S. Chemical thromboprophylaxis is not necessary to reduce risk of thromboembolism with tranexamic acid after total hip arthroplasty. J Arthroplasty. 2017;32:641-4. https://doi.org/10.1016/j.arth. 2016.07.048.

37. Nishihara S, Hamada M. Does tranexamic acid alter the risk of thromboembolism after total hip arthroplasty in the absence of routine chemical thromboprophylaxis? Bone Joint J. 2015;97-B:458-62. https://doi. org/10.1302/0301-620X.97B4.34656.

38. Yue C, Kang P, Yang P, et al. Topical application of tranexamic acid in primary total hip arthroplasty: a randomized double-blind controlled trial. J Arthroplasty. 2014;29:2452-6. https://doi.org/10.1016/j.arth.2014.03.032.

39. Yi Z, Bin S, Jing Y, et al. Tranexamic acid administration in primary total hip arthroplasty: a randomized controlled trial of intravenous combined with topical versus single-dose intravenous administration. J Bone Joint Surg Am. 2016;98:983-91. https://doi.org/10.2106/JBJS.15.00638.

\section{Publisher's Note}

Springer Nature remains neutral with regard to jurisdictional claims in published maps and institutional affiliations.

Ready to submit your research? Choose BMC and benefit from:

- fast, convenient online submission

- thorough peer review by experienced researchers in your field

- rapid publication on acceptance

- support for research data, including large and complex data types

- gold Open Access which fosters wider collaboration and increased citations

- maximum visibility for your research: over $100 \mathrm{M}$ website views per year

At BMC, research is always in progress.

Learn more biomedcentral.com/submissions 